\title{
Time Course of Error Detection and Correction in Humans: Neurophysiological Evidence
}

\author{
Antoni Rodríguez-Fornells, Arthur R. Kurzbuch, and Thomas F. Münte \\ Department of Neuropsychology, Otto von Guericke University, 39112 Magdeburg, Germany
}

\begin{abstract}
Using event-related brain potentials, the time course of error detection and correction was studied in healthy human subjects. A feedforward model of error correction was used to predict the timing properties of the error and corrective movements. Analysis of the multichannel recordings focused on (1) the error-related negativity (ERN) seen immediately after errors in response- and stimulus-locked averages and (2) on the lateralized readiness potential (LRP) reflecting motor preparation. Comparison of the onset and time course of the ERN and LRP components showed that the signs of corrective activity
\end{abstract}

preceded the ERN. Thus, error correction was implemented before or at least in parallel with the appearance of the ERN component. Also, the amplitude of the ERN component was increased for errors, followed by fast corrective movements. The results are compatible with recent views considering the ERN component as the output of an evaluative system engaged in monitoring motor conflict.

Key words: error correction; error detection; error-related negativity; ERN; lateralized readiness potential; LRP; response conflict; event-related brain potentials; ERPs
To adapt their behavior to an ever-changing environment, humans need to be able to monitor their performance and to detect and correct any errors. The present investigation seeks to delineate the time course of error detection and correction in humans using event-related brain potentials (ERPs) (Münte et al., 2000). A negative ERP component labeled error-related negativity (ERN) has been isolated, appearing immediately after committing errors (Falkenstein et al., 1990; Gehring et al., 1993, 1995). A large part of the ERN can be explained by a source in the anterior cingulate cortex (Gemba et al., 1986; Dehaene et al., 1994; Carter et al., 1998, Luu and Tucker, 2001). Two competing models have been proposed to explain the cognitive mechanism underlying the ERN. One model associates the ERN to an error-detection mechanism (Gehring et al., 1993; Falkenstein et al., 1995). Because the peak of the ERN appears too early ( $\sim 60 \mathrm{msec}$ after the response) to depend on sensory and proprioceptive information, it has been assumed that the ERN reflects the output of a feedforward control mechanism (Bernstein et al., 1995). This mechanism compares an internal goal with the predicted consequences of the ongoing movement, made available through the efference copy (Shadmehr and Mussa-Ivaldi, 1994; Wolpert et al., 1995; Desmurget and Grafton, 2000) (see Fig. 1). An internal "error signal" is generated if a mismatch is detected by the system.

Alternatively, the ERN conflict-detection model holds that the ERN merely reflects the degree of response conflict experienced by subjects (Cohen et al., 2000; Botvinik et al., 2001). This theory fits well with data showing ERNs or anterior cingulate activity for correct responses (Carter et al., 1998; Luu et al., 2000; Scheffers and Coles, 2000; Vidal et al., 2000) and responses showing a higher degree of motor conflict (Barch et al., 2000; Gehring and

Received Feb. 19, 2002; revised Sept. 3, 2002; accepted Sept. 6, 2002.

This work was supported by grants from the Deutsche Forschungsgemeinschaft (T.F.M.). A.R.F. was supported by a postdoctoral fellowship from the Spanish Government. We thank Christine Matthes for running the control experiment.

Correspondence should be addressed to Dr. Thomas F. Münte, Department of Neuropsychology, Otto von Guericke University, Universitätsplatz 2, Gebäude 24, 39106 Magdeburg, Germany. E-mail: thomas.muente@medizin.uni-magdeburg.de. Copyright (C) 2002 Society for Neuroscience $0270-6474 / 02 / 229990-07 \$ 15.00 / 0$
Fencsik, 2001; van Veen et al., 2001). As pointed out by Paus (2001), the ERN conflict-detection model emphasizes the "evaluative" nature of the anterior cingulate cortex. Other authors, however, have suggested that the ERN or anterior cingulate activations are indexing a more general evaluative system that processes the motivational significance of events, including but not limited to errors and response conflict situations (Bush et al., 2000).

Less evidence is available about the neural implementation of error corrections targeted in the current study. Bearing in mind that error correction is one of the fastest cognitive processes (Rabbitt, 1966a,b; Cooke and Diggles, 1984), it was predicted that the corrective motor command would be triggered as soon as the evaluative system has accumulated enough evidence. Critically, the onset of the corrective movement will be indexed with the onset of the lateralized readiness potential (LRP) (Gratton et al., 1988; Smid et al., 1992). Thus, the relative timing of the LRP and ERN components in the present experiment could be used to infer the time course of error correction and detection. Two control experiments (noncorrection instructions and unilateral vs bilateral movements) demonstrated the sensitivity of the LRP and ERN to error correction.

\section{MATERIALS AND METHODS}

Error correction. Sixteen right-handed neurologically healthy subjects (Ss) participated in the experiment (four women; mean \pm SD age, $24.6 \pm$ 4.5 years) after giving informed consent according to the declaration of Helsinki. All of them were paid for their participation.

The Eriksen flanker task (Eriksen and Eriksen, 1974) was used in which subjects are required to focus on the letter in the center of a visual array of five letters, designated as "target," and to respond with the right or left hand depending on which of two target letters (H or S) had appeared. Four flanker letters surrounding the target letter either favored the target response (compatible trials, HHHHH or SSSSS) or primed the other response (incompatible trials, HHSHH or SSHSS). To optimize the number of errors, $40 \%$ of compatible trials and $60 \%$ of incompatible trials were presented. Each stimulus array subtended $\sim 2.5^{\circ}$ of visual angle in width, and a fixation line was presented in the middle of the computer monitor just below the target letter in the array. In addition, in one-half of the trials, the target letter appeared degraded, by 


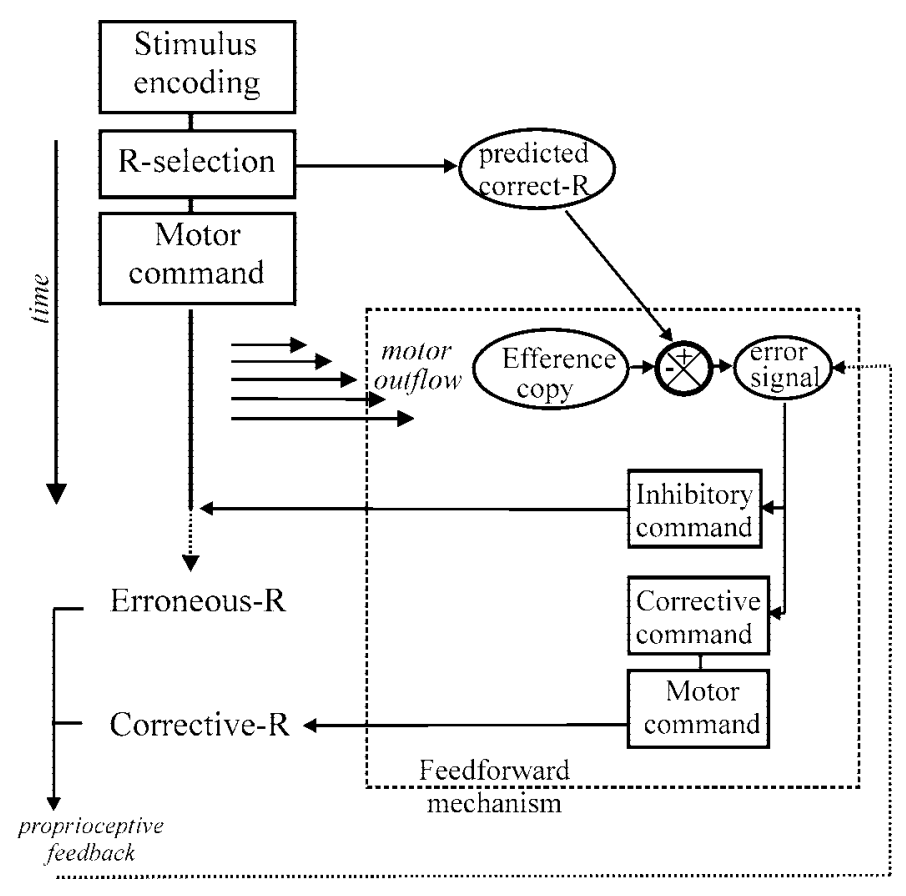

Figure 1. Simplified diagram of the different stages of information processing (boxes) and internal representations (ellipses) involved when an erroneous response $(R)$ is produced (adapted from Desmurget and Grafton, 2000) (Wolpert et al., 1995; Coles et al., 2001). The large dotted square delineates the feedforward control mechanism used to inhibit and correct the erroneous response. When a wrong selection of the motor command is produced, a motor copy of the activated on-line response is generated (the efference copy) and compared with the predicted correct response (Angel, 1976). If a mismatch is produced, an error signal is elicited, and immediately a stop command is triggered to abort the response. If the erroneous response bypasses this command, the system triggers the corrective motor command as fast as possible. An additional potential source of information for the corrective system might be proprioceptive input from the limb (see dotted arrow). It has been suggested that proprioceptive information can modify EMG responses with a delay of only 70 msec (Crago et al., 1976).

removing $\sim 70 \%$ of the pixels (the flankers were maintained nondegraded). Duration of the stimuli was $100 \mathrm{msec}$, and the stimulus onset asynchrony between two successive stimuli was $900 \mathrm{msec}$. Letter-hand assignments were counterbalanced between subjects.

Ss participated in two sessions. In the first session, subjects were initially trained with 400 trials to reach a reaction time (RT) baseline level that could be used as a starting point to fix the final deadline RT for each subject. After this baseline period, a series of 40 trials was administered, and the subjects received feedback about their performance. The goal of this procedure was to aim for a reaction time that would yield $\sim 15 \%$ of errors (see below). After six of such blocks, subjects performed between 20 and 22 experimental blocks of 200 trials each. Between blocks, subjects were given at least 2 min to relax and stretch. Correction of the errors was forbidden. This session will only be used as a control or baseline condition (hereafter referred as correction forbidden) to assess the differences between the error-LRPs when correcting and not correcting errors.

In the second session, the main experiment, error correction was required whenever Ss detected a performance error (Fig. 1). Using the same RT deadline procedure, subjects performed between 24 and 26 experimental blocks. Subjects were encouraged to correct their erroneous responses as fast as possible, before the appearance of the next stimulus. All of the analyses reported in this study are based on this error-correction data, except for the comparisons with the control experiment and the error-correction forbidden condition from the first session.

Control experiment: responding with and without switching hands. The aim of this control experiment was to mimic the motor activity performed when correcting errors in the previous experiment, in which both hands were recruited sequentially. Ss were required to make left-right responses assigned to an $\mathrm{H}$ or $\mathrm{S}$ presented in the center of the screen (fixed stimulus onset asynchrony of $900 \mathrm{msec}$; stimuli subtended $0.5^{\circ}$ in width; a fixation line was always present just below the target letter). During 400 trials, single-hand responses were required. In the switching hand condition ( 400 additional trials), Ss had to press first with the assigned response hand and then to switch immediately and respond with the other hand. Therefore, trials required either left-right or right-left responses. Both conditions and letter-hand assignments were counterbalanced. As in the bimanual condition, the motor command of the second ("switch") response could be prepared in parallel with the execution of the first response, and the comparison of the unilateral and bilateral response LRPs in the control experiment with correct and error-corrective LRPs in the main experiment was thought to be revealing with regard to the point in time at which the corrective response began to be prepared in the main experiment.

Eight right-handed subjects, who had not taken part in the main experiment, participated in the control study (age, $23 \pm 2.1$ years; six women). No analysis of erroneous responses were made in this experiment, and only correct trials were included in the averages.

ERPs. The electroencephalogram (EEG) was recorded from 29 scalp locations, including all standard 10/20 system positions against the algebraic mean of the activity at the mastoid electrodes (bandpass, 0.01-70 $\mathrm{Hz}$; digitization rate, $250 \mathrm{~Hz}$ ) using tin electrodes mounted in an elastic cap. Vertical eye movements and horizontal eye movements were recorded by bipolar montages. After artifact rejection based on individualized amplitude criteria, the EEG signal was averaged separately for each stimulus-response combination for epochs of $1024 \mathrm{msec}(-300,724$ msec in response-locked averages; -100, 924 in stimulus-locked averages). Baselines used for response-locked averages were from -300 to $-200 \mathrm{msec}$ for LRPs and from -50 to $0 \mathrm{msec}$ for the ERN component. A low-pass filter ( $8 \mathrm{~Hz}$, half-amplitude cutoff) was applied in all of the computations and averages reported.

For each subject, at least 100 artifact-free error trials for each response hand were obtained. Thus, at least 200 trials were available for the computation of the ERN component. The mean number of error responses included in the averages was $216 \pm 80$ for the correctionforbidden session responses and $260 \pm 102$ for the correction-encouraged session $\left(t_{(15)}=-1.7 ; p=0.098\right)$. From this pool of errors, $238 \pm 81$ were right-hand errors, and $238 \pm 79$ were left-hand errors $\left(t_{(15)}<1\right)$. The median reaction time of the corrective responses was determined separately for every subject using the trials free of artifacts. This median was used to create response-locked averages for "slow" and "fast" corrective responses for every subject.

LRPs were assessed by using C3 and C4 electrode locations, in which the amplitude of the readiness potential is maximum (Kutas and Donchin, 1980). The LRP is computed by a double subtraction as shown in the following equation: $\mathrm{LRP}=$ left hand $(\mathrm{C} 4-\mathrm{C} 3)-$ right hand $(\mathrm{C} 4-\mathrm{C} 3)$.

Left and right hands refer to the expected correct hand, and (C4 - C3) is the difference in electrical potential between these electrodes (Gratton et al., 1988; Coles, 1989; Smid et al., 1992). The resulting LRP component is negative if subjects produce correct responses and positive for error trials. In some statistical analyses, the polarity of the error-LRP was inverted to perform statistical analyses and to allow visual comparison in the figures.

For statistical analysis, mean amplitude measures were obtained and entered into ANOVA statistics with the Huynh-Feldt epsilon correction applied as necessary. All tests involving electrode $\times$ condition interactions were performed on vector normalized data (McCarthy and Wood, 1985). Onset latencies of the LRP were determined via a stepwise series of one-tailed serial $t$ tests (step size of $4 \mathrm{msec}$ ) (Schmitt et al., 2000). For each test, data from a time window of $40 \mathrm{msec}$ were averaged (i.e., point of measure, $\pm 20 \mathrm{msec}$ ); the onset latency was defined as the point at which five consecutive $t$ tests showed a significant difference from zero $(p<0.05)$.

\section{RESULTS}

\section{Correcting erroneous responses}

The mean overall reaction time was $360 \pm 34 \mathrm{msec}$. The mean reaction time needed to correct an error was $212 \pm 40 \mathrm{msec}$. As expected, error responses were faster $(\sim 36 \mathrm{msec})$ than correct responses: $342 \pm 35 \mathrm{msec}$ versus $378 \pm 35\left(t_{(16)}=7.3 ; p<0.001\right)$. Percentage of hits was $82 \%$, and the percentage of errors was $16 \%$. 


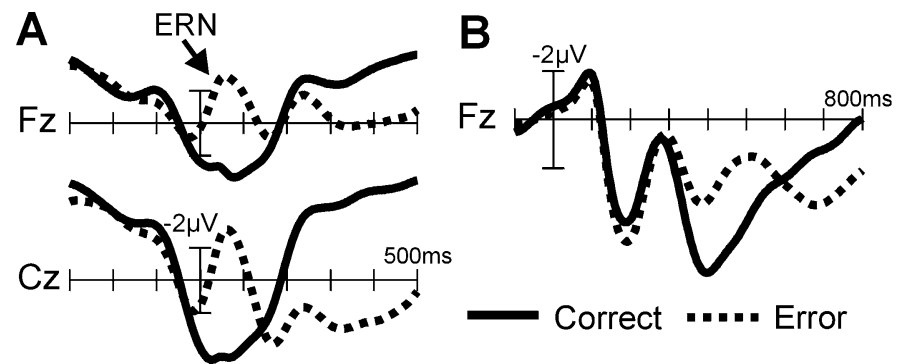

Figure 2. A, Response-locked grand average for correct and error trials. A clear ERN component is elicited immediately after the response. $B$, The stimulus-locked averages are illustrated for a single frontal electrode. Notice the increased negativity, $\sim 300$ and $600 \mathrm{msec}$ for the error trials.

The ERN component was clearly present in the responselocked averages (Fig. $2 A$ ) and appeared immediately after the response with a frontocentral distribution. It was followed by a positive parietal component (error positivity) (Falkenstein et al., 1995). An ANOVA was performed on the three midline electrodes [Fz (midline frontal), $\mathrm{Cz}$ (midline central), and $\mathrm{Pz}$ (midline parietal)] and for type of trial (correct vs error). Errors showed an increased negativity quantified as the mean amplitude in the $0-100 \mathrm{msec}$ window $\left(F_{(1,15)}=51.2 ; p<0.001\right)$. The frontocentral distribution of the ERN was reflected in the significant interaction of electrode $\times$ type of trial $\left(F_{(2,30)}=14.2 ; p<\right.$ 0.001 ; at $\mathrm{Cz}$, mean amplitude errors of $-2.4 \pm 3.3 \mu \mathrm{V}$ and correct responses of $2.75 \pm 2.5$ ). The stimulus-locked ERPs are shown in Figure $2 B$. Again, an enhanced negativity was observed for the errors with an onset of $\sim 250 \mathrm{msec}$, which corresponds to the ERN in the response-locked averages.

\section{Time course of error correction}

Hereafter, the term correct-LRP refers to the LRP for correct responses, error-LRP refers to the LRPs computed for the error responses, and corrective-LRP indicates the LRP to the corrective response after the error. The correct-LRP differed from zero between -124 and $86 \mathrm{msec}$ ( $210 \mathrm{msec}$ significant interval for negative LRP) (Fig. $3 A$ ). The error-LRP was significant between -116 and $12 \mathrm{msec}$, being more positive than $0(128 \mathrm{msec}$ interval). From 56 until $308 \mathrm{msec}$ ( $252 \mathrm{msec}$ interval), as a sign of the corrective response, the error-LRP differed from 0 in the negative direction.

As can be observed in Figure $3 A$, the onset of the correctiveLRP is earlier than that of the correct-LRP. The onset latency of the corrective-LRP was $-156 \mathrm{msec}$ (significant until $84 \mathrm{msec} ; 240$ msec interval) (Fig. 3B). When contrasting the correct-LRP with the corrective-LRP, these were significantly different between -136 and $80 \mathrm{msec}$. Thus, these data suggest that (electrophysiologically) it takes more time to prepare the corrective response. In Figure 4A (left), the polarity of the error-LRP is inverted to facilitate comparison with the LRP to the correct responses and to determine the onset of the motor activity for the corrective response. The correct-LRP began to differ from the inverted error-LRP at $-68 \operatorname{msec}\left(t_{(15)}=-2.29 ; p<0.05\right)$. This time point can be taken as an estimate for the time at which the corrective command is already initiated.

We contrasted this time point with the moment at which subjects began their second hand movement in the control experiment (Fig. 4A, right). The mean reaction time for unimanual movements was faster than for the switching condition $(366 \pm 35$ vs $405 \pm 36$ msec; $\left.t_{(7)}=-3.8 ; p<0.01\right)$. The time needed for
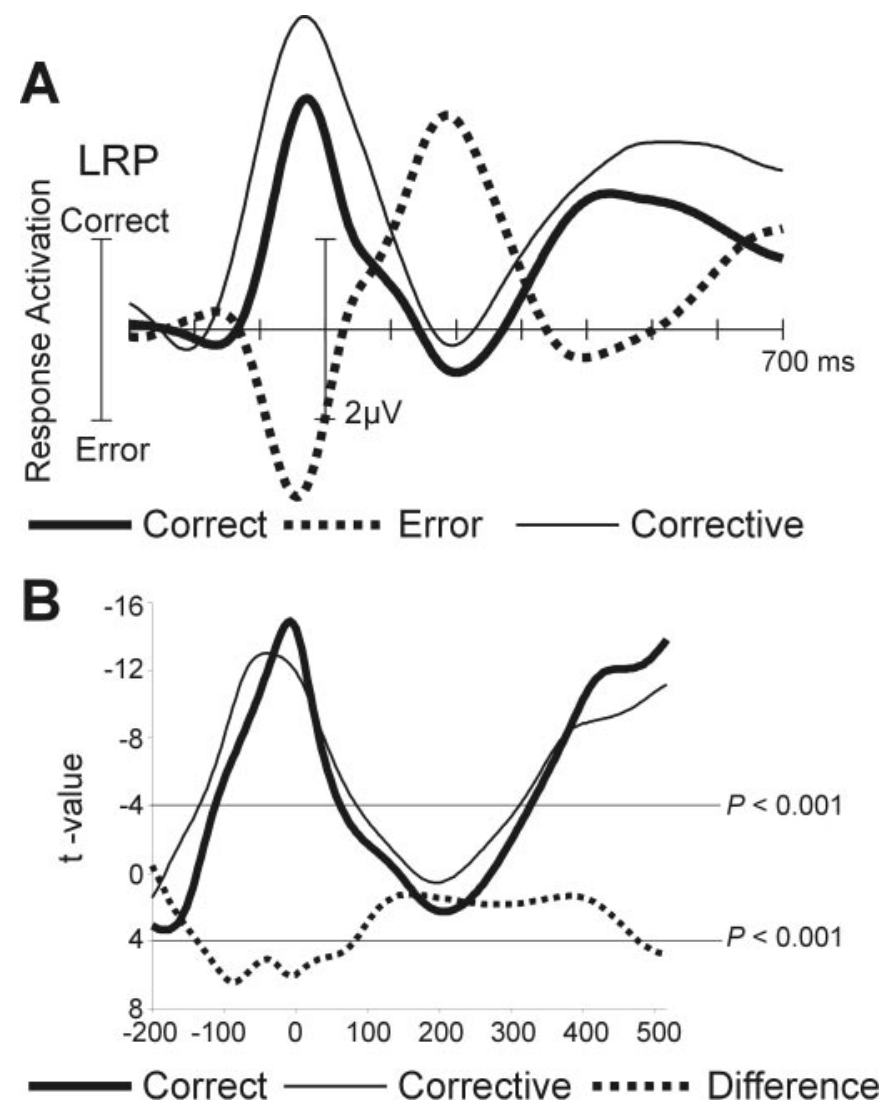

Figure 3. A, Response-locked LRP in the correction-encouraged condition for the correct, error, and corrective responses. LRP was obtained by double subtraction from the lateral central electrode sites $\mathrm{C} 3$ and $\mathrm{C} 4$. B, The $t$ test plot of the differences tested.

switching hands was $214 \pm 27 \mathrm{msec}$ (second reaction time). Despite the differences between both tasks (correction vs switching), the LRP waveforms look very similar. In the control experiment, both LRPs (one-hand and switching) began to develop at the same time, $\sim 120 \mathrm{msec}$ before the response, and no differences were observed between both conditions in the onset latency (paired $t$ test; $t_{(7)}<-0.55$ ). However, 50 msec later, preparation of the contralateral response starts in the switching condition, and correct responses from one-hand and switching conditions began to differ at $-76 \operatorname{msec}\left(t_{(7)}=-2.46 ; p<0.05\right)$. This difference remained significant until $332 \mathrm{msec}\left(t_{(7)}=-2.37 ; p<0.05\right)$. Notice that this comparison attests to the ability of LRP to differentiate between the overlapping activity of responses of different hands.

In Figure $4 B$, data from the correction-forbidden condition of the main experiment are shown. Notice the large overlap between both conditions, correction forbidden and encouraged, in particular for correct responses. To get an additional estimate for the time at which the corrective motor command is triggered, the error-LRPs of the correction-forbidden and correctionencouraged conditions were compared (Fig. $4 B$, right). A statistically reliable difference between the error-LRPs was found from $-8 \operatorname{msec}\left(t_{(15)}=-2.51 ; p<0.05\right)$ onward, until 316 msec. In contrast, no such early differences between conditions were seen in the response-locked ERPs to correct or error responses (Fig. $4 B)$. Also, it is noteworthy that the ERN in the correctionforbidden condition was smaller than in the correctionencouraged condition $\left(F_{(1,15)}=6.83 ; p<0.02\right)$. 
A Correcting errors

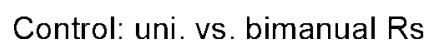

B
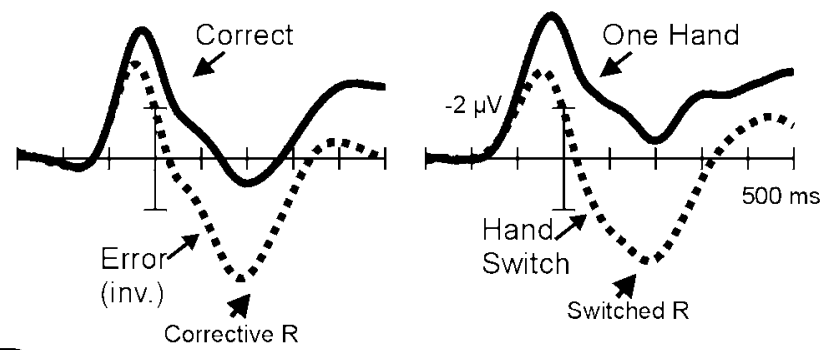

Correct responses

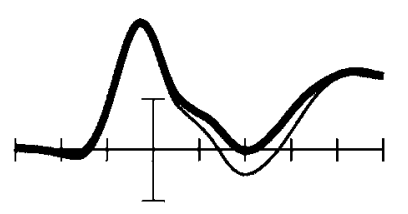

Correction forbidden - Correction encouraged

Response-locked averages

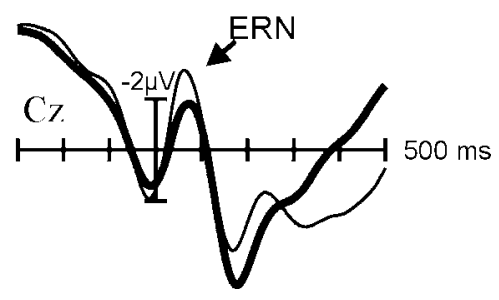

Figure 4. A, LRPs for the correction-encouraged condition and the control experiment requiring unimanual or successive bimanual responses. The LRP for the error response was inverted for a better comparison. Notice the faster onset of the switched response compared with the corrective response. $B$, Comparison between LRPs for the error-correction condition and the baseline session, in which error correction was forbidden. Notice that the corrective command is initiated before the erroneous button press occurs. In contrast, the ERN for erroneous responses from both conditions depicted below does not show such early differences.

\section{Fast corrections versus slow corrections}

The corrective responses were divided according to the median of the reaction time of the correction in every subject. Thus, ERPs for fast-corrective trials and slow-corrective trials were obtained (Fig. 5). Note that averages time-locked to the error response were used, thus neutralizing the possible RT differences in the main response (errors). The mean reaction time for the fast- and slow-corrective responses was $160 \pm 37$ and $264 \pm 43 \mathrm{msec}$, respectively. To rule out the possibility that the latency difference of fast and slow corrections was not attributable to a difference in the latencies of the preceding error responses, we computed the error RTs separately for these two categories. For the errors that were followed by fast corrections, the mean reaction time was $338 \pm 34 \mathrm{msec}$; the errors followed by slow corrections were slightly but reliably faster, at $308 \pm 35 \operatorname{msec}\left(t_{(15)}=11.7 ; p<\right.$ $0.001)$. Thus, the difference in corrective RTs for fast and slow correction $(104 \mathrm{msec})$ cannot be attributed to the difference in the RT of the preceding error $(30 \mathrm{msec})$.

Importantly, as shown in Figure 5, the onsets of the LRP and ERN responses did not follow the same pattern. The LRP for fast

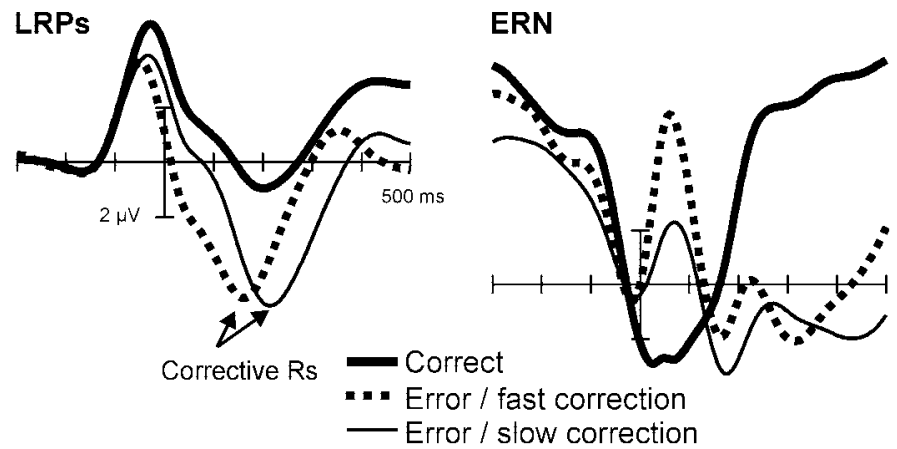

Figure 5. Response-locked LRP and ERN in the correction-encouraged condition computed as a function of whether corrective responses were fast or slow (median split). The error-LRP polarity was inverted for a better comparison with the correct LRP.

corrections began to diverge from the LRP for slow corrections at $-24 \mathrm{msec}$ (relative to the error response). The two LRPs remained different until 160 msec. Figure 5 also shows the ERN component for fast and slow corrections. The amplitude of the ERN is larger in the fast corrections compared with slow corrections. We tested this effect at frontocentral locations for the 0-100 msec time window. Fast-corrected movements showed a significant increase compared with slow corrections at $\mathrm{Fz}\left(F_{(1,15)}=9.97\right.$; $p<0.01$; fast corrections, $-2.6 \pm 2.4 \mu \mathrm{V}$ vs slow corrections, $-1.9 \pm 2.4 \mu \mathrm{V})$ and at $\mathrm{Cz}\left(F_{(1,15)}=24.6 ; p<0.001\right.$; fast corrections, $-3.5 \pm 3.5 \mu \mathrm{V}$ vs slow corrections, $-1.3 \pm 3.4 \mu \mathrm{V})$.

\section{Is speed of error correction depending on the quality of information?}

Based on the feedforward model (Fig. 1), the correction process might be triggered by an internal error signal, which depends on the comparison between the actual motor command (efference copy) and the mental representation of the predicted correct response. If the stimulus information is reduced (e.g., when it is degraded), the "correct mental representation" might be delayed, and, therefore, the error correction mechanisms should be triggered later as well. For testing this prediction, easy trials comprising incompatible nondegraded stimuli and difficult trials comprising incompatible degraded stimuli were compared. Incompatible trials were chosen to yield a sufficient number of errors to obtain clean LRPs.

The stimulus-locked LRPs are depicted in Figure 6 for degraded and nondegraded stimuli from the correction-encouraged and correction-forbidden conditions. With regard to the correct stimuli, in both conditions, the LRP onset was earlier in the nondegraded compared with the degraded trials (forbidden: nondegraded, $212 \mathrm{msec}$ and degraded, $304 \mathrm{msec}$; encouraged: nondegraded, $216 \mathrm{msec}$ and degraded, $308 \mathrm{msec}$; all $t$ values $>2.4$; $p<0.05$ ). Thus, the reaction time and LRP depended on the quality of the information in the correct trials. This was not the case for the error trials. For the correction-encouraged condition, the onset of the error-LRP in the nondegraded and degraded trials was virtually identical (nondegraded, $204 \mathrm{msec}$, degraded, $200 \mathrm{msec}$, all $t$ values $>2.4 ; p<0.05$ ). As can be derived from Figure 6 (bottom right), the two error-LRPs are clearly different with regard to the correction phase, with the downswing of the LRP being much earlier in the nondegraded condition, leading to a significant difference between the two error-LRPs between 284 and $400 \mathrm{msec}(t>-2.34 ; p<0.05)$. Thus, whereas the latency of the error response did not depend on the quality of information, 


\section{Correction forbidden Correction encouraged}
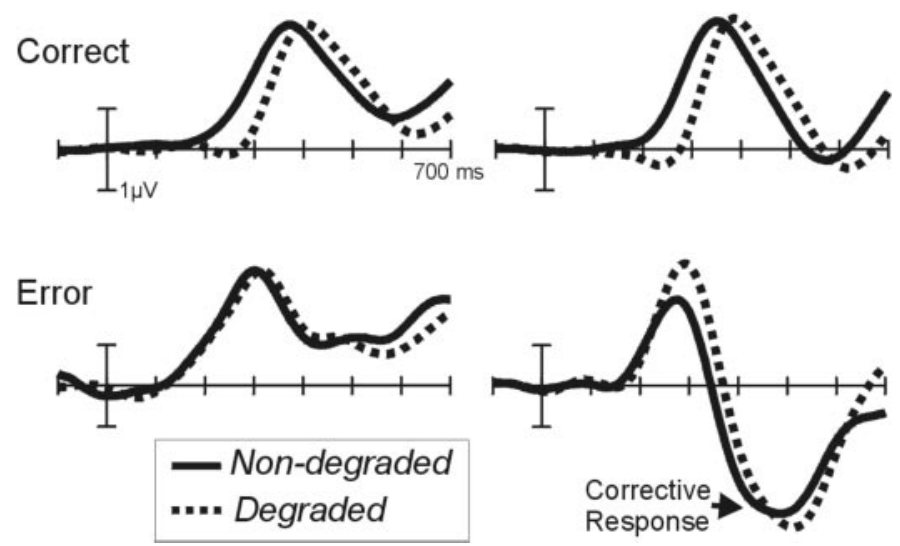

Figure 6. Stimulus-locked LRPs for easy (incompatible nondegraded) and difficult (incompatible degraded) trials. The LRPs are presented for correct and error trials for both correction-encouraged and correctionforbidden conditions. Whereas the onset of the LRP depended on the perceptual quality of the stimulus for the correct trials, the onset of the error-LRPs was independent of stimulus quality. On the other hand, the latency of the corrective response, indicated by the downswing in the errorLRP, varied as a function of the quality of the eliciting response.

the latency of the corrective response did. In the correctionforbidden condition on the other hand, error-LRPs for degraded and nondegraded stimuli virtually overlapped with no statistical differences (Fig. 6, bottom left).

\section{DISCUSSION}

To our knowledge, this is the first electrophysiological study assessing the time course of error detection and correction. Two major points will be outlined: (1) error correction is implemented before or at least in parallel with the appearance of the ERN component, and (2) the amplitude of ERN component appears to reflect the degree of motor conflict when correcting errors.

\section{Time course of error correction}

The feedforward model of error correction (Fig. 1) suggests that the error-correction process might be triggered immediately after the elicitation of an internal error signal, which depends on the representation of the predicted "correct response" and efference copy of the on-line motor command. The error-LRP began to differ from the correct-LRP as early as $68 \mathrm{msec}$ before the response (Fig. 4A), thus giving an estimate of the time point at which the corrective response is triggered. Importantly, this time point precedes the onset of the ERN component. An alternative estimate of the onset of correction was obtained by comparing the error-LRPs in both correction conditions (Fig. 6B), which began to differ $8 \mathrm{msec}$ before the response. In both cases, the conclusion is warranted that the ERN component appears after error correction is already underway or, at the very best, at the same time. This result is incompatible with the assumption that the process underlying the ERN triggers error correction. Thus, if the ERN is taken as an index of (conscious) error monitoring (Scheffers and Coles, 2000; Coles et al., 2001), a second (nonconscious) internal error signal must precede the ERN and initiate the correction process. This partial independence of error detection and correction converges with data on very fast corrections of complex movements (Goodale et al., 1986; Castiello et al., 1991) and is also supported by two additional comparisons. First, when comparing error trials followed by either slow or fast corrections, a dissociation between the elicitation of the correction mechanisms and the ERN was found (Fig. 5). Whereas a clear delay was present in the LRP for the slow corrective responses, the ERN latency was not affected. The second comparison pertains to the discriminability of the critical stimuli. We predicted an earlier onset of the correction mechanism in trials that were easier to discriminate (incompatible degraded trials vs the incompatible nondegraded ones), because a mental representation of the predicted correct response should be available faster in these trials. In the correction-encouraged condition, the stimulus-locked error-LRP for the easy trials hardly lateralized above zero (Fig. 6 ), because the correction mechanism was implemented immediately. In contrast, in the difficult trials, a longer interval of lateralization of the error-LRP was found before the onset of the corrective-LRP.

Before accepting this interpretation, a possible alternative account might be considered, however. This account states that the corrective responses obtained in the correction-encouraged condition do not occur in response to, i.e., subsequent to the detection of, an error but rather are slow correct responses prepared in parallel with the faster errors. A revealing comparison in this regard is shown in Figure $4 B$, which depicts the LRPs obtained in the correction-forbidden and correction-encouraged conditions. LRPs to the error trials are virtually identical in both conditions up to $20 \mathrm{msec}$ before the response, rendering it unlikely that the correct response is prepared in parallel with the error. A second argument against this alternative account is based on the control experiment. Here, the LRPs in bimanual and unimanual conditions diverged earlier from each other than the correct and error-LRPs in the correction-encouraged condition of the main experiment (Fig. 4A).

\section{The nature of the ERN component}

A second aim of this study was to investigate the influence of the correction process on the ERN. The amplitude differences of the ERN to trials followed by fast and slow corrections are most revealing in this respect. The ERN has a higher amplitude for the trials, which were followed by fast corrective movements compared with the ones that were corrected slower (Fig. 5). This follows directly from the ERN conflict-detection model (see introductory remarks) that predicts that coactivation of two conflicting motor channels (in this case, error response and corrective response) should lead to an increase of the ERN (Botvinik et al., 2001). As for fast corrections, the temporal overlap of the motor programs for error and corrective responses is greater, and a larger ERN is expected. In the error-detection model of the ERN, the ERN amplitude is driven by the mismatch between the representation of the computed correct response and the efference copy of the actual (error) response (Coles et al., 2001). For error trials followed by slow corrections, it might be the case that not enough stimulus information is available at the time of the error for detection to occur effectively, leading to a smaller ERN and slower corrections. For fast corrections, more information might be available, hence a larger ERN and faster corrections. A third account of the ERN states that the amplitude of this component indexes the activity of a general evaluative system concerned with the motivational significance of the error rather than with the response conflict per se (Luu and Tucker, 2001). The present data are compatible with such an account, if one assumes that the motivational level of errors is higher in a situation in which correction is allowed and also higher for trials accompanied by fast corrections. Thus, the current results are 
indifferent with regard to the different accounts of the ERN component.

An unresolved issue is the relationship of the ERN component to the conscious detection of errors. Although it has been stated that the ERN is linked to the conscious perception of errors (Dehaene et al., 1994; Scheffers and Coles, 2000), it might also be the case that the ERN is only reflecting an internal unconscious error signal and that conscious perception is followed later. In the current data set, the ERN follows the corrective command (indexed by the LRP) in time. Because the internal error signal needs to precede the corrective command, it cannot underlie the ERN. This favors the interpretation that the internal error signal itself is unconscious and that the ERN is probably associated with the conscious perception of the errors. This view is supported by findings from Luu et al. (2000), who found a linear increase in the amplitude of the ERN with increasingly late responses in a task defining late responses as errors.

The existence of automatic error correction has been demonstrated recently (Pisella et al., 2000) (see also Rabbitt, 1968). In this study, subjects were making pointing reactions with their hand. In some trials, the target was displaced unexpectedly to the left or to the right, requiring the inhibition of the pointing response. Subjects could not avoid to make automatic hand movement corrections to the displacements, similar to the control situation, which, in a different group of subjects, required an adjustment of the movement in the direction of the displacement. In this situation, a clear conflict emerged between the correction system, apparently acting automatically, and the voluntary motor intentions to inhibit the on-line response.

With regard to the generality of the current findings, it is important to consider that they pertain to a particular kind of error correction, i.e., the generation of a new (or corrective) motor command in the presence of an erroneous initial motor response. This is clearly different from paradigms in the motor domain, such as so-called double-step experiments involving subliminal target displacements (Prablanc and Martin, 1992). In a recent brain imaging study using this paradigm, a neural network including the cerebellum, posterior parietal cortex (PPC), and primary motor cortex was demonstrated to be involved in error correction (Desmurget et al., 2001). PPC has also been demonstrated to be important the correction of hand trajectories (Desmurget et al., 1999; Pisella et al., 2000). For example, a patient with bilateral lesions of the PPC failed to show automatic error corrections of his movements but was able to make slow and deliberate motor corrections (Pisella et al., 2000). Desmurget and Grafton (2000) consequently have proposed a model of error correction in which the PPC is controlling the adequacy of the ongoing motor response, predicting the movement end point and detecting discrepancies between the expected and the predicted position. The error signal is sent to the cerebellum, which in turn corrects ongoing activity in the primary motor cortex.

This specific on-line error-correction mechanism differs in many aspects from the one studied here, both with regard to its functional characteristics and to the brain systems involved. Whereas on-line corrections in the double-step paradigm are performed even if the target displacement is not consciously detected (Prablanc and Martin, 1992), the error-correction mechanism studied in the present investigation is related to conscious detection and the intentional release of a corrective motor command using the contralateral limb. The anterior cingulate cortex is clearly involved in the type of paradigm used in the present investigation (Carter et al., 1998) but not in the on-line corrections in the double-step paradigm (Desmurget et al., 2001).

\section{REFERENCES}

Angel RW (1976) Efference copy in the control of movement. Neurology 26:1164-1168.

Barch DM, Braver TS, Sabb FW, Noll DC (2000) Anterior cingulate and the monitoring of response conflict: evidence from an fMRI study of overt verb generation. J Cognit Neurosci 12:298-309.

Bernstein PS, Scheffers MK, Coles MGH (1995) "Where did I go wrong?" A psychophysiological analysis of error detection. J Exp Psychol Hum Percept Perform 21:1312-1322.

Botvinick MM, Braver TS, Barch DM, Carter CS, Cohen JD (2001) Conflict monitoring and cognitive control. Psychol Rev 108:624-652.

Bush G, Luu P, Posner MI (2000) Cognitive and emotional influences in anterior cingulate cortex. Trends Cogn Sci 4:215-222.

Carter CS, Braver TS, Barch DM, Botvinick MM, Noll D, Cohen JD (1998) Anterior cingulate cortex, error detection, and the on-line monitoring of performance. Science 280:747-749.

Castiello U, Paulignan Y, Jeannerod M (1991) Temporal dissociation of motor responses and subjective awareness. Brain 114:2639-2655.

Cohen JD, Botvinick M, Carter CS (2000) Anterior cingulate and prefrontal cortex: who's in control. Nat Neurosci 3:421-423.

Coles MGH (1989) Modern mind-brain reading: psychophysiology, physiology and cognition. Psychophysiology 26:251-269.

Coles MGH, Scheffers MK, Holroyd CB (2001) Why is there an ERN/Ne on correct trials? Response representations, stimulus-related components, and the theory of error-processing. Biol Psychol 56:173-189.

Cooke JD, Diggles VA (1984) Rapid error correction during human arm movements: evidence for central monitoring. J Motor Behav $16: 348-363$.

Crago PE, Houk JC, Hasan Z (1976) Regulatory actions of human stretch reflex. J Neurophysiol 39:925-935.

Dehaene S, Posner MI, Tucker DM (1994) Localization of a neural system for error detection and compensation. Psychol Sci 5:303-305.

Desmurget M, Grafton S (2000) Forward modeling allows feedback control for fast reaching movements. Trends Cogn Sci 4:423-431.

Desmurget M, Epstein CM, Turner RS, Prablanc C, Alexander GE, Grafton ST (1999) Role of the posterior parietal cortex in updating reaching movements to a visual target. Nat Neurosci 2:563-567.

Desmurget M, Grea H, Grethe JS, Prablanc C, Alexander GE, Grafton ST (2001) Functional anatomy of nonvisual feedback loops during reaching: a positron emission tomography study. J Neurosci 21:2919-2928.

Eriksen BA, Eriksen CW (1974) Effects of noise letters upon the identification of target letters in a non-search task. Percept Psychophys 16:143-149.

Falkenstein M, Hohnsbein J, Hoormann J, Blanke L (1990) Effects of errors in choice reaction tasks on the ErP under focused and divided attention. In: Psychophysiological brain research (Brunia CHM, Gaillard AW K, Kok A, eds), pp 192-195. Tilburg, The Netherlands: Tilburg UP.

Falkenstein M, Hohnsbein J, Hoormann J (1995) Event-related potential correlates of errors in reaction tasks. In: Perspectives of eventrelated brain potentials research (Karmos G, Molnár M, Csépe V, Czigler I, Desmedt JE, eds), pp 287-296. Amsterdam: Elsevier.

Gehring WJ, Fencsik DE (2001) Functions of the medial frontal cortex in the processing of conflict and errors. J Neurosci 21:9430-9437.

Gehring WJ, Gross B, Coles MGH, Meyer DE, Donchin E (1993) A neural system for error detection and compensation. Psychol Sci 4:385390.

Gehring WJ, Coles MGH, Meyer DE, Donchin E (1995) A brain potential manifestation of error-related processing. In: Perspectives of eventrelated brain potentials research, EEG Suppl 44 (Karmos G, Molnár M, Csépe V, Czigler I, Desmedt JE, eds), pp 261-272. Amsterdam: Elsevier.

Gemba H, Sasaki K, Brooks VB (1986) "Error" potentials in limbic cortex (anterior cingulate area 24) of monkeys during motor learning. Neurosci Lett 70:223-227.

Goodale MA, Pelisson D, Prablanc C (1986) Large adjustments in visually guided reaching do not depend on vision of the hand or perception of target displacement. Nature 320:748-750.

Gratton G, Coles MGH, Sirevaag EJ, Eriksen CW, Donchin E (1988) Pre- and poststimulus activation of response channels: a psychophysiological analysis. J Exp Psychol Hum Percept Perform 14:331-344.

Kutas M, Donchin E (1980) Preparation to respond as manifested by movement-related brain potentials. Brain Res 202:95-115.

Luu P, Tucker DM (2001) Regulating action: alternating activation of midline frontal and motor cortical networks. Clin Neurophysiol 112:1295-1306.

Luu P, Flaisch T, Tucker DM (2000) Medial frontal cortex in action monitoring. J Neurosci 20:464-469.

McCarthy G, Wood CC (1985) Scalp distributions of event-related po- 
tentials: an ambiguity associated with analysis of variance models. Electroencephalogr Clin Neurophysiol 62:203-208.

Münte TF, Urbach TP, Düzel E, Kutas M (2000) . Event-related brain potentials in the study of human cognition and neuropsychology. In: Handbook of neuropsychology, Vol 1 (Boller F, Grafmann J, Rizolatti $\mathrm{G}$, eds), pp 139-235. Amsterdam: Elsevier.

Paus T (2001) Primate anterior cingulate cortex: where motor control, drive and cognition interface. Nat Rev Neurosci 2:417-424.

Pisella L, Grea H, Tilikete C, Vighetto A, Desmurget M, Rode G, Boisson D, Rossetti Y (2000) An "automatic pilot" for the hand in human posterior parietal cortex: toward reinterpreting optic ataxia. Nat Neurosci 3:729-736.

Prablanc C, Martin O (1992) Automatic control during hand reaching at undetected two-dimensional target displacements. J Neurophysiol 67:455-469.

Rabbitt PMA (1966a) Error correction time without external error signals. Nature 212:438.

Rabbitt PMA (1966b) Errors and error correction in choice-response tasks. J Exp Psychol 71:264-272.
Rabbitt PMA (1968) Three kinds of error signalling responses in a serial choice task. Q J Exp Psychol 21:159-170.

Scheffers MK, Coles MG (2000) Performance monitoring in a confusing world: error-related brain activity, judgements of response accuracy, and types of errors. J Exp Psychol Hum Percept Perform 26:141-151.

Schmitt BM, Münte TF, Kutas M (2000) Electrophysiological estimates of the time course of semantic and phonological encoding during implicit picture naming. Psychophysiology 37:473-484.

Shadmehr R, Mussa-Ivaldi FA (1994) Adaptative representation of dynamics during learning of a motor task. J Neurosci 14:3208-3224.

Smid HGOM, Mulder G, Mulder LJM, Brands GJ (1992) A psychophysiological study of the use of partial information in stimulus-response translation. J Exp Psychol Hum Percept Perform 18:1101-1119.

van Veen V, Cohen JD, Botvinick MM, Stenger VA, Carter CS (2001) Anterior cingulate cortex, conflict monitoring, and levels of processing. NeuroImage 14:1302-1308.

Vidal F, Hasbroucq T, Grapperon J, Bonet M (2000) Is the "error negativity" specific to errors? Biol Psychol 52:109-128.

Wolpert DM, Ghahramani Z, Jordan MI (1995) An internal model for sensorimotor integration. Science 269:1880-1882. 